Rev. Elev. Méd. vét. Pays trop., 1978, 31 (1) : 27-31.

\title{
Note sur la microflore bactérienne intestinale d'un nématode : Thelazia rhodesi
}

\author{
par J. BLANCOU $\left({ }^{*}\right)$, G. VASSILIADES $\left({ }^{*}\right)$ et X. MATTEI $\left({ }^{* *}\right)$
}

\section{RÉSUMÉ}

L'intestin de Thelazia rhodesi récolté au Sénégal, et observé au microscope électronique, contient une population bactérienne importante. Ces bactéries, ensemencées sur milieu gélosé, se révèlent généralement être des cultures pures, monospécifiques (genres Corynebacterium et Aeromonas en particulier). Leur pouvoir pathogène, faible in vitro, pourrait devenir important in vivo où ils vivent soustraits à l'action des substances bactériostatiques de l'œil.

\section{INTRODUCTION}

L'étude systématique de la microflore bactérienne des nématodes parasites est rarement entreprise. Cela tient à la difficulté d'une telle étude, ces helminthes vivant généralement dans des cavités naturelles où pullule déjà une microflore abondante.

Toutefois, lorsqu'elle est réalisée, elle révèle que la microflore propre au nématode est souvent beaucoup plus réduite que celle de son environnement, comme l'ont récemment démontré les travaux de E. M. DUNNING (1) dans le cas des oxyures de la souris.

Nous avons donc tenté un tel travail avec Thélazia rhodesi, DESMARET, 1827 (Spirurida ; Thelazioidea) encouragés en cela par deux constatations préliminaires :

1. L'environnement de ce nématode est très peu contaminé, puisqu'il est constitué par le cul du sac conjonctival de l'œil des bovins où sont sécrétées des substances bactériostatiques d'origine lacrymale.

2. L'observation de coupes de Thelazia rhodesi au microscope électronique (photo $\mathrm{n}^{\circ} 1$ )

(*) Laboratoire national de l'Elevage et de Recherches vétérinaires, B. P. 2057, Dakar, République du Sénegal.

(**) Département de Biologie animale, Faculté des Sciences, Université de Dakar, République du Sénégal.

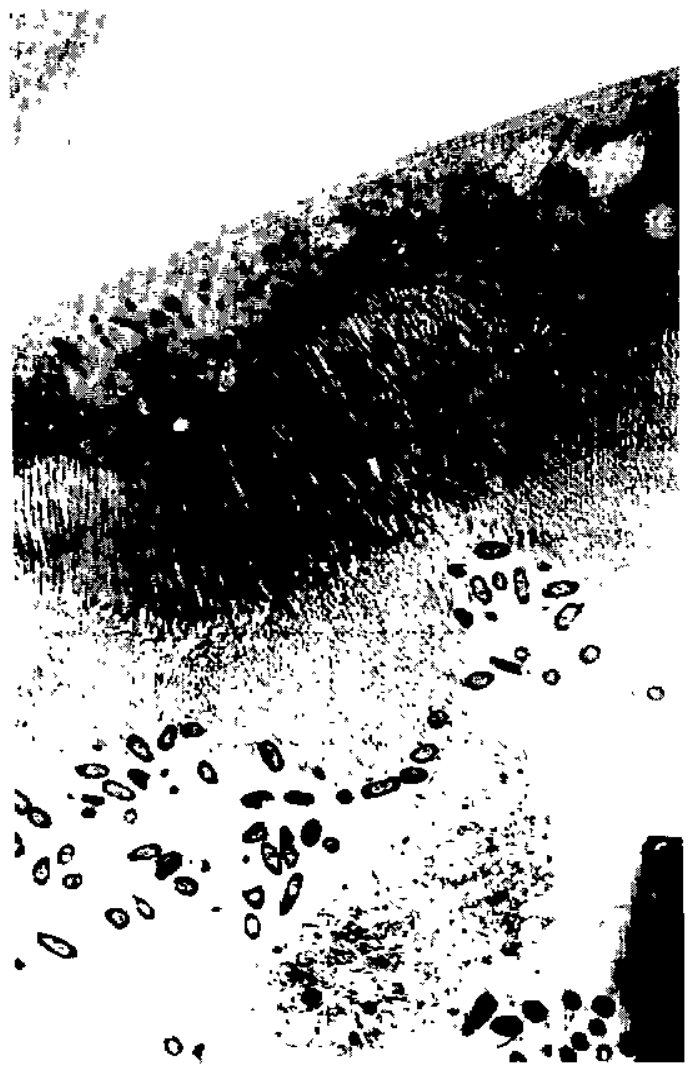

Photo $\mathrm{n}^{0}$ 1. Bactéries in situ dans l'intestin de Thelazia rhodesi. Coupe photographiée au microscope électronique $(\times 3600)$. 
révèle la présence d'assez nombreuses bactéries $(1,8 \times 0,6 \mu$ environ $)$ de morphologie très uniforme.

C'est le résultat de nos essais d'isolement de ces bactéries qui fait l'objet de la présente note.

\section{MATÉRIEL ET MÉTHODES}

\section{MATÉRIEL}

- Le matériel d'étude est constitué par des exemplaires vivants de Thelazia rhodesi, prélevés à l'aide d'une pince fine dans le cul-de-sac conjonctival des bovins tués à l'abattoir de Dakar.

- Le matériel bactériologique est le matériel habituel d'un laboratoire de bactériologie anaIytique.

\section{MÉTHODES}

\section{- Préparation de l'inoculum}

Le produit à analyser bactériologiquement (inoculum) est préparé selon la technique suivante :

- les exemplaires vivants de Thelazia (formes immatures, ou adultes $\hat{\delta}$ et $O$ ) sont extraits à l'aide d'une pince histologique flambée, égouttés sur papier filtre stérilisé et aussitôt placés dans de l'eau physiologique stérile.

Ils séjournent $5 \mathrm{mn}$ dans ce bain agité régulièrement. Après ce délai, l'opération est recommencée dans un nouveau bain, 3 fois consécutives.

Cette série de bains stériles a pour but de détacher le maximum de bactéries extérieures éventuellement adsorbées sur la cuticule du nématode. Après le dernier rinçage les Thelazia sont placées dans un mortier stérile et broyés au pilon en présence d'eau physiologique ( $1 \mathrm{ml}$ pour 10 Thelazia) : c'est ce broyat, une fois parfaitement homogénéisé, qui constitue l'inoculum à analyser.

\section{- Analyse bactériologique}

Six prélèvements de $0,1 \mathrm{ml}$ sont ensemencés à la surface de 6 géloses: 2 géloses nutritives ordinaires, 2 géloses additionnées de 10 p. 100 de sang de mouton, 2 géloses additionnées de 10 p. 100 de sérum de cheval. Chaque gélose reçoit donc, en moyenne, l'inoculum correspondant à la totalité d'un Thelazia.

Une partie des 6 géloses est incubée à $37^{\circ}$ en aérobiose, l'autre en anaérobiose (jarre anaérobie saturée de $\mathrm{CO}_{2}+\mathrm{H}_{2}$ ), à $37^{\circ}$ également.

Soixante-douze heures plus tard, les colonies bactériennes sont dénombrées, et chaque colonie différente fait l'objet d'un repiquage en vue de son identification ultérieure.

\section{RESULTATS}

Nos observations ont porté sur 68 Thelazia. Leurs résultats sont les suivants :

\section{Cultures positives}

Toutes les cultures aérobies ont été positives comme le montre le tableau ci-dessous, c'est-àdire que le corps des Thelazia contient bien des bactéries (vues au microscope électronique), et qu'elles sont vivantes.

\begin{tabular}{|c|c|c|c|c|c|c|c|c|}
\hline \multirow{2}{*}{$17^{\circ}$} & \multirow{2}{*}{ lois } & \multirow{2}{*}{$\begin{array}{l}\text { Nombre } \\
\text { de } \\
\text { Phe Lazia }\end{array}$} & \multicolumn{3}{|c|}{ Culture anaérobie } & \multicolumn{3}{|c|}{ Culture aérobie } \\
\hline & & & $\mathrm{GN}$ & GSE & GSG & $\mathrm{GN}$ & GSE & GS G \\
\hline A & Hoût & 7 & - & - & - & - & + & + \\
\hline B & Août & 14 & - & + & + & + & + & + \\
\hline $\mathrm{C}$ & Janvier & 8 & - & - & - & - & + & + \\
\hline D & Février & 12 & - & - & - & + & + & + \\
\hline E & Avril & $\begin{array}{c}15 \\
\text { (adultes) }\end{array}$ & - & - & - & + & + & + \\
\hline F & Avril & $\begin{array}{c}12 \\
\text { (inivatures) }\end{array}$ & & - & - & + & + & + \\
\hline
\end{tabular}

QN = Cêlose nutritive ordinaire; GSE = Gếlose au sérum; GSG = Gélose au sang. - = absence de culture $;+=$ prësence de culture. 


\section{Nombre de bactéries vivantes}

Si l'on admet que chaque bactérie revivifiable donne naissance à une colonie sur gélose, la moyenne calculée sur les 68 Thelazia est de 12 bactéries environ par nématode. Compte tenu de la densité plus élevée visible au microscope électronique, on peut penser, soit que les bactéries visibles sont presque toutes mortes, soit que leur nombre varie beaucoup d'un sujet à l'autre (peut-être même nul pour certains sujets).

\section{Morphologie des colonies}

L'examen des colonies révèle un fait assez surprenant : la microflore intestinale est constituée par une culture presque pure de la même bactérie (photos $n^{o s} 2$ et 3 ). Ainsi, selon nos essais, la proportion des colonies différentes de l'espèce dominante observée est de 1 p. 100 (essai A); 0 p. 100 (essai B) ; 2,3 p. 100 (essai C) ; 1,2 p. 100 (essai D) ; 0,5 p. 100 (essai E) et 1 p. 100 (essai F), taux "normal » pour un inoculum de cette origine.

Il y a donc homogénéité de la microflore pour l'ensemble des Thelazia provenant du même prélèvement.

\section{Identification des bactéries}

Seules les bactéries aérobies ont fait l'objet d'une identification $\left(^{*}\right)$ de genre, la seule souche anaérobie isolée n'ayant pas pu être repiquée.

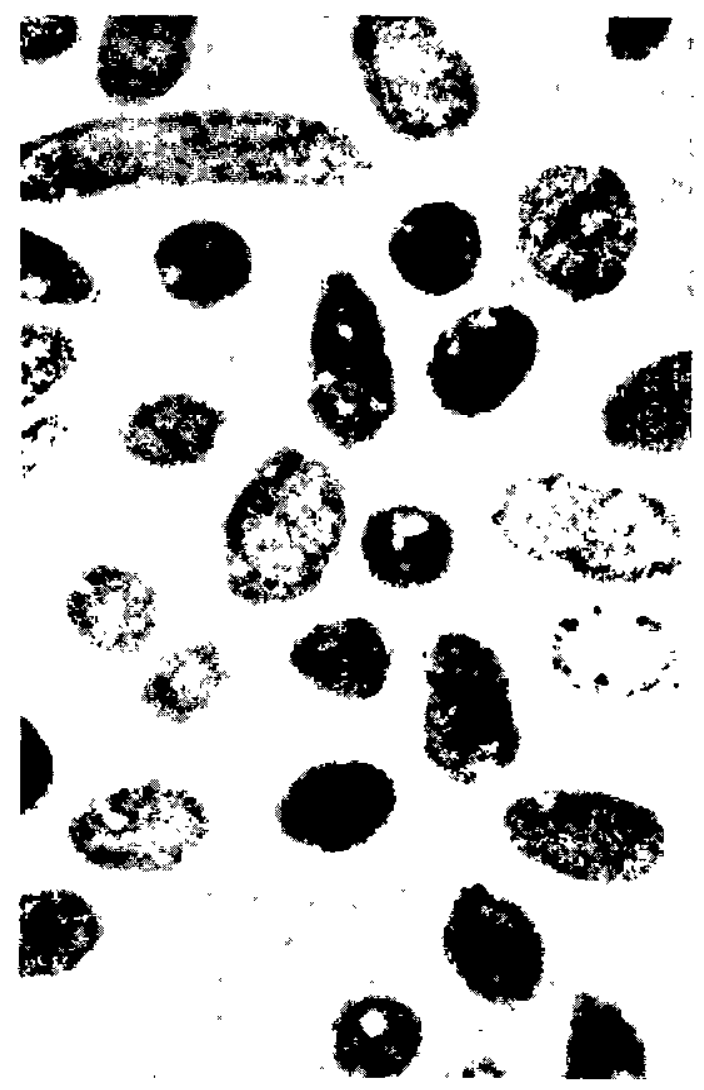

Photo $n^{\circ} 2$. Bactéries isolées sur gélose. Coupe photographiée au microscope électronique $(\times 18000)$.

(*) Nous remercions vivement le Dr J. L. CARTEL, de l'Institut Pasteur de Dakar, pour l'aide qu'll nous a apportée dans ces identifications.

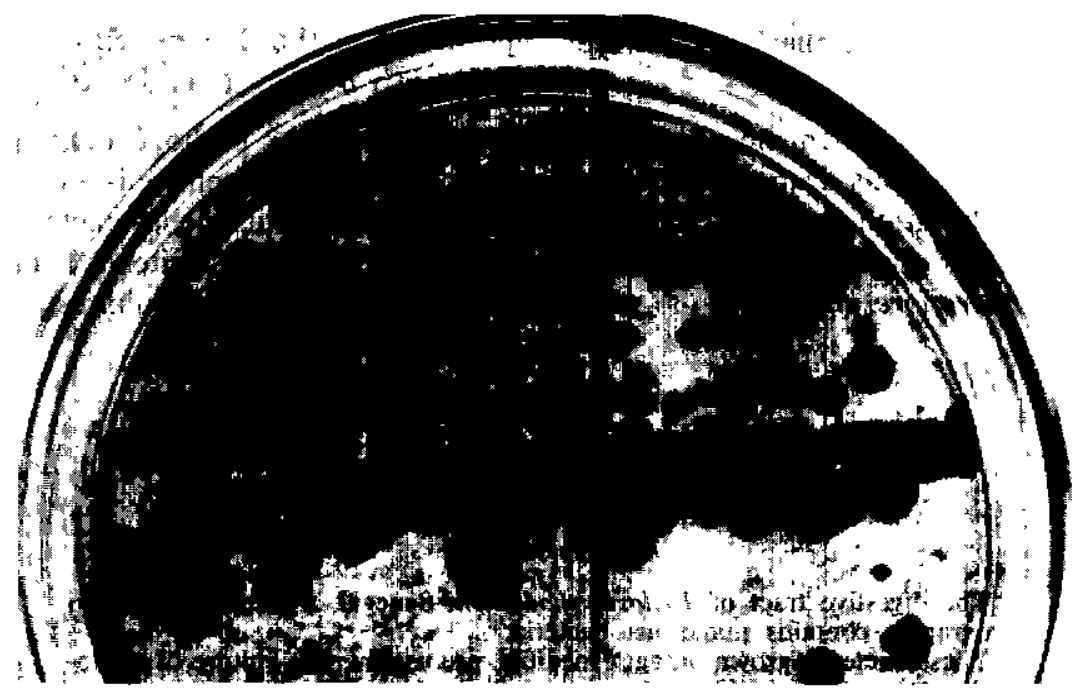

Photo $n^{\circ}$ 3. - Culture sur gélose-sérum ( 72 h à $37^{\circ}$ ) du broyat de 14 Thelazia rhodesi. 
Elles se classent toutes dans 3 genres ou espèces :

- Gaffkya tetragena (non sérophile à l'isolement),

- Corynebacterium (sérophile à l'isolement),

- Aeromonas hydrophila (non sérophile à l'isolement).

Ces deux dernières espèces pourraient correspondre, en dimensions et morphologie, à celles visibles in situ au microscope électronique. Habituellement trouvées dans le milieu extérieur, ces trois bactéries ne sont considérées que comme «pathogènes occasionnels » pour les mammifères.

\section{Pouvoir pathogène}

Le pouvoir pathogène des 3 genres bactériens a été recherché sur souris (inoculation conjonctivale, sous-cutanée, intra-péritonéale) et sur moutons et bovins (instillation dans le cul-de-sac conjonctival), sans aucun succès, du moins lorsqu'on utilise les corps bactériens récoltés sur gélose. Par contre la culture en bouillon d'Aeromonas, qui contient donc les métabolites excrétés par les corps bactériens, peut provoquer une conjonctivite transitoire chez le bovin.

\section{DISCUSSION}

L'intestin de Thelazia rhodesi renferme donc une microflore bactérienne de caractère très particulier. Cette microflore est constituée par une population comprenant un nombre très réduit d'espèces, qui se multiplient en culture pure dans cet intestin.

Les espèces hébergées semblent ne pas varier d'un individu à l'autre, mais d'un prélèvement (c'est-à-dire d'une population donnée) à l'autre : tous les individus issus d'une même population auraient la même microflore intestinale.
On sait que les bactéries associées à certains nématodes peuvent avoir un pouvoir pathogène pour l'hôte de l'helminthe : cette «bactérionématodose » est un fait bien établi, dans deux cas, chez les insectes $(2,3)$. Les bactéries isolées des Thelazia pourraient-elles aussi être pathogènes pour l'œil de leur ruminant-hôte ? On pourrait le penser, d'autant plus que les Thelazia effectuent une partie de leur cycle de développement chez des insectes diptères (muscidae). Nos tentatives infructueuses de reproduire expérimentalement un pouvoir pathogène net avec les bactéries isolées, sembleraient infirmer cette hypothèse.

Toutefois, ces essais ne peuvent exclure une action pathogène des bactéries in vivo, dans Thelazia parasité, par excrétion permanente des métabolites toxiques sensibilisants. Le Thelazia, en protégeant les bactéries des substances bactériostatiques sécrétées par l'œil, leur permet en effet de se multiplier et d'exercer impunément leur action toxique éventuelle.

\section{CONCLUSION}

L'intestin du nématode Thelazia rhodesi contient généralement une population bactérienne en culture pure, monospécifique.

Les bactéries en cause (genres Gaffkya, Corynebacterium et Aeromonas dans nos essais au Sénégal) varient selon l'origine de la population des nématodes, mais non selon les individus.

Il n'a pas toujours été possible de démontrer une action pathogène directe de ces bactéries, isolées in vitro, vis-à-vis de l'œil des bovins.

Mais une action pathogène in vivo, par action toxique ou hypersensibilisation progressive, n'est pas exclue puisque les bactéries intestinales de Thelazia sont soustraites à l'action bactériostatique des sécrétions oculaires.

\section{SUMMARY}

A note on intestinal microflora of a round-worm :

\section{Thelazia rhodesi}

The digestive tract of Thelazia rhodesi, in Senegal, as seen on electron micrographs, contains numerous bacteria.

These bacteria, grown on agar medium, are usualy pure culture of monospecific population (particularly genus Corynebacterium and Aeromonas). Their pathogenicity, weak in vitro, could increase in vivo where growing bacteria may be protected from ocular bacteriostasis. 


\section{RESUMEN}

Nota sobre la microflora bacteriana intestinal de un nemátodo :

\section{Thelazia rhodesi}

El intestino de Thelazia rhodesi recogido en Senegal, y observado con el micróscopo electrónico, contiene una población bacteriana importante.

Dichas bacterias,sembradas sobre medio gelosado, generalmente son cultivos puros, monoespecíficos (particularmente generos Corynebacterium y Aeromonas).

Su poder patógeno, mediano in vitro, podria hacerse importante in vivo dónde viven substraidos a la acción de las substancias bacterioestáticas del ojo.

\section{BIBLIOGRAPHIE}

1. DUNNING (E. M.), WRIGHT (K, A.), Isolation of bacteria from the intestines of the mouse pinwornus and from their hosts. Can. J. Zool., 1970 (6) : 14431444.

2. LYSENKO (O.), WEISER (J.). Bacteria associated with the nematode Neoplectana carpocapsae and the pathogenicity of the complex for Galleria Mellonela larvae. J. Invertebrate Path., 1974, 24 (3) : 233-236.

3. POINAR (G. O.). Description and biology of a new insect parasitic rhabditoid Heterorhabdites bacteriophora n. gen. n. s. p. (Rhabditida : Heterorhabditidae n. fam.). Nematologica, 1975, 21 (4) : 463-478. 